\section{O papel das lideranças e dos partidos políticos na sobrevivência das democracias}

\section{The role of leaders and political parties in the survival of democracies}

LEVITSKY, Steven \& ZIBLAT, Daniel. Como as democracias morrem. 2018. Rio de Janeiro, Zahar. E-book.

\section{Vítor Eduardo Veras de Sandes-Freitas \\ (iD) http://orcid.org/0000-0002-0186-6709}

Universidade Federal do Piauí (UFPI), Teresina - PI, Brasil.E-mail: vitorsandes@ufpi.edu.br

DOI: $10.1590 / 3410104 / 2019$

Com o título original How democracies die: what history reveals about our future (Nova York, Crown; Londres, Viking), o livro escrito por Steven Levitsky e Daniel Ziblatt foi lançado em janeiro de 2018 e traduzido e publicado no Brasil no mesmo ano.

Apesar de tratar do caso dos Estados Unidos à luz da análise de experiências de deterioração democrática em outros países, a obra se insere no debate geral em torno da manutenção das democracias e propiciou reflexóes inclusive acerca do posicionamento dos candidatos à presidência do Brasil - nas eleiçôes de 2018 - em relação à democracia e às condiçôes necessárias para preservá-la. ${ }^{1}$

Diferentemente de estudos anteriores, que mostram que o desenvolvimento econômico gera um efeito positivo sobre a manutenção de democracias (como em Przeworski et al., 1997), Levitsky e Ziblatt questionam que fatores levariam então ao enfraquecimento das democracias, mesmo em contextos de desenvolvimento econômico. Em seu estudo, consideram o papel da agência um aspecto fundamental a essa compreensão.

Os autores alertam que a morte das democracias não é um fenômeno que ocorre abruptamente, mas um processo de corrosão gradual de suas regras formais e informais, que garantem, em linhas gerais, a tolerância em relação aos opositores (tolerância mú- tua) e o uso das prerrogativas institucionais de forma comedida (reserva institucional). Esse alerta recai, portanto, sobre os compromissos das lideranças políticas e, consequentemente, dos partidos políticos com tais regras, fundamentais para a existência de um ambiente efetivamente democrático.

No desenvolver do argumento, os autores resgatam a tradição de estudos sobre presidencialismo, adequados para tratar o caso norte-americano e os regimes latino-americanos; deixam de lado a análise centrada nos efeitos das causas e optam pela análise centrada nos mecanismos das causas, em particular, na participação direta de líderes autoritários no esgarçamento e derrocada da democracia no mundo. Com esse fim, selecionaram exemplos de regimes políticos democráticos que tiveram rápida deterioração e que nos mostram como os respectivos atores políticos contribuíram para o seu enfraquecimento e até mesmo à sua ruína. Não analisam todos os casos de declínio da democracia - não é esse o objetivo da obra. O foco recai sobre os casos em que líderes tiveram papel central na deterioração da democracia, servindo de base para a análise do caso norte-americano.

Isso se deve, em parte, à escolha editorial por um público-alvo mais abrangente que o acadêmico: o leitor leigo que se interesse pelo tema. Assim, a escrita é de fácil compreensão e a tradução, bastante clara. $\mathrm{Ou}$ seja, do ponto de vista de um modelo acadêmico mais convencional, o livro carece de maior detalhamento sobre as escolhas teóricas (como uma discussão mais ampla sobre as razóes de se focar na agência dos atores políticos) e metodológicas (sobre a escolha de certos casos e não de outros, por exemplo, e também quanto à sistemática de levantamento de dados).

Quando os autores abordam os casos, a explicação do processo de deterioração das democracias se centra exclusivamente na agência, enquanto a literatura sobre o tema também atribui importância às variáveis institucionais e econômicas na análise do processo de sobrevivência das democracias. Seria importante considerar também esses aspectos para compreendermos em que contexto os líderes políticos atentam contra a tolerância mútua e a reserva institucional, pois corre o risco de atribuirmos somente aos agentes a responsabilidade de sustentar as democracias, quando, na verdade, as democracias 
podem definhar em consequência de inúmeras variáveis, por exemplo, pelo arranjo institucional adotado e pelo desempenho econômico do país. Portanto, os autores poderiam ter explorado melhor a relevância dessas variáveis para o debate em que a obra se insere. Mesmo com essas ponderaçóes, o livro traz importantes contribuiçóes para a literatura e faz reflexóes extremamente relevantes para pensarmos a vitalidade das democracias mundo afora.

$\mathrm{Na}$ introdução, os autores alertam para os perigos que corre a democracia dos Estados Unidos, ao abrir mão da tolerância mútua, que garante "o entendimento de que partes concorrentes se aceitem umas às outras como rivais legítimas", e também da contenção, ou seja, "a ideia de que os políticos devem ser comedidos ao fazerem uso de suas prerrogativas institucionais”. A raiz desses problemas estaria no sectarismo que polariza politicamente o país, estendendo-se para questóes de raça e cultura. Levada ao extremo, essa polarização seria capaz de findar com democracias, principalmente se autocratas tiverem a possibilidade de serem eleitos, o que daria a legitimidade para que se subverta a democracia. Os nove capítulos do livro se centram, em linhas gerais, nesse fio condutor.

No primeiro capítulo, "Aliança fatídicas", os autores tratam sobre como líderes autoritários podem alcançar o poder via eleições. Esse foi o caso de Hitler, Fujimori e Chávez, que, em diferentes tempos históricos e com as devidas particularidades contextuais, levaram a retrocessos na democracia. Uma crise econômica pode despertar o apoio popular a um outsider, com a promessa de trazer desenvolvimento ao país (Hitler é um exemplo).

Assim, os autores apresentam um modelo para identificar candidatos autoritários, com base em contribuiçóes de Linz (1978). Eles podem ter um ou mais destes comportamentos: (1) rejeitam as regras democráticas do jogo (ou têm um compromisso fraco com elas); (2) negam a legitimidade dos oponentes políticos; (3) toleram ou encorajam a violência; e (4) são propensos a restringir liberdades civis de oponentes, inclusive da mídia. Esses comportamentos consistem tanto de açôes contrárias às regras formais quanto às regras informais.

Ao se centrarem nos líderes, os autores fizeram uma escolha teórica importante, não evidenciada claramente no livro: destacam o papel da agência na deterioração ou na manutenção da democracia, ou seja, a capacidade que os indivíduos, nesse caso, as lideranças, têm de expressar seus interesses e, por consequência, de afetar as instituições. As lideranças, ao tomar decisóes políticas, sem observar as regras (formais e informais), podem tensionar as instituições democráticas.

Os autores alertam que cabe aos partidos políticos evitar líderes com algum desses comportamentos, que, no limite, atentam contra a democracia. Para eles, "os partidos políticos são os guardióes da democracia”, filtros que restringem a ascensão de líderes autoritários e selecionam candidatos comprometidos com o jogo democrático.

A partir dessas reflexões, Levitsky e Ziblatt apresentam no segundo capítulo, "Guardiōes da América”, como os partidos políticos se tornaram filtros importantes no processo de seleção de candidaturas nos Estados Unidos. Apesar da "veia autoritária" norte-americana, nas palavras dos autores, os partidos políticos foram capazes de evitar a ascensão de candidatos autoritários pelas duas principais agremiaçóes do país: o Partido Democrata e o Partido Republicano. O processo de seleção de candidatos à Presidência dos Estados Unidos, durante muito tempo, era decidido em "bastidores esfumaçados", ou seja, por meio dos insiders partidários, responsáveis por indicar os candidatos dos partidos. Existia um controle interno aos indicados, o que evitava outsiders, aventureiros e candidatos pouco comprometidos com o jogo democrático.

No entanto, esse mecanismo carregava, em si, uma tensão em relação aos eleitores, pois restringia a escolha às opçóes definidas de forma não democrática pelos insiders partidários. Esse sistema começou a ruir em 1968, tendo como marco o grande protesto em Chicago no dia da Convenção do Partido Democrata, conhecido por Batalha da Avenida Michigan. A partir daquele momento, os democratas criaram a Comissão McGovern-Fraser, que produziu um relatório final, em 1971, indicando a mudança do sistema de escolha de candidatos, o que levou à criação do sistema de primárias vinculantes: o candidato mais votado na eleição interna do partido se torna o candidato à presidência da República pelo partido. Tanto democratas quanto 
republicanos acabaram adotando as recomendaçóes do relatório e, partir de 1972, a maior parte dos delegados dos dois partidos seriam eleitos em primárias nos estados.

O novo modelo democratizaria o processo de seleção de candidatos, mas, ao mesmo tempo, impunha um perigo: e se um candidato populista e descomprometido com a democracia fosse o escolhido nas primárias? Havia, entretanto, limites à viabilização de um candidato com esse perfil: "precisava conquistar aliados entre os doadores, editores de jornais, grupos de interesse e políticos de âmbito estadual, como governantes, prefeitos, senadores e congressistas". Os obstáculos eram uma espécie de "primária invisível", o que garantiria a indicação de um candidato com o crivo dos líderes partidários, que funcionariam como filtros para a escolha nas primárias. Os limites formais (recursos) e informais (apoios e fidelidades) impunham aos outsiders a difícil tarefa de se viabilizarem como candidatos pelos partidos. Os insiders partidários continuavam controlando a porta de entrada para novas lideranças, inclusive, de líderes autoritários.

Os mecanismos de controle, no entanto, fracassaram. Isso é abordado no terceiro capítulo, "A grande abdicação republicana”, que trata especificamente das eleições de 2016 nos Estados Unidos, mostrando como os mecanismos de controle a candidatos autoritários foram falhos e levaram Donald Trump à presidência do país. Conforme destacam os autores, o grande fator explicativo do fenômeno foi o baixo poder que as lideranças partidárias tiveram em barrar Trump. Além de primárias abertas, já existentes nos Estados Unidos, houve a "explosão da mídia alternativa” em um ambiente que favorecia a viabilização de celebridades como candidatos. Com a nova dinâmica midiática, o processo eleitoral foi mais aberto do que nunca, viabilizando a escolha de uma celebridade e outsider nas primárias do Partido Republicano. No processo de escolha de candidatos, a polarização já estabelecida nas eleiçóes anteriores foi mantida. Apoiadores dos republicanos continuaram a apoiar e a votar no Partido Republicano. Os "guardiōes do partido" poderiam ter conduzido o processo tanto na "primária invisível” quanto nas primárias propriamente ditas e, até mesmo, nas próprias eleiçóes, alertando sobre o perigo que representava a escolha de um candidato como Trump, mas eles falharam.

No quarto capítulo, "Subvertendo a democracia", os autores argumentam que os líderes autoritários eleitos tendem a contornar o Congresso, utilizando os recursos que estão à mão, como o uso de decretos executivos, a exemplo do que ocorreu no caso do Peru, de Fujimori. A falta de disposição em negociar com o Legislativo é uma característica distintiva de líderes autoritários, o que pode levar a açóes mais centralizadoras e, consequentemente, menos democráticas ou, em última instância, até mesmo à dissolução do Congresso, fato este levado a cabo por Fujimori em 5 de abril de 1992, por exemplo.

Por isso, declaram os autores: "a democracia é um trabalho árduo". Depende do cumprimento de regras formais e informais da democracia, aceitando os freios e contrapesos institucionais e, também, os posicionamentos contrários, que impóem mudanças na agenda de governo inicialmente proposta. Líderes autoritários tentam driblar o pacto democrático em nome do combate à corrupção, do aperfeiçoamento da democracia e mesmo de resguardar a segurança nacional, como destacam os autores.

Contemporaneamente, a democracia tem ruído em um processo lento e gradual de corrosão dos pactos democráticos, com mudanças institucionais, perseguição a opositores, tudo sob o "verniz de legalidade”, como na Venezuela e na Nicarágua. Momentos de crise podem dar o suporte necessário para que governantes tomem medidas autoritárias, principalmente quando os cidadãos passam a temer pelo próprio bem-estar.

As regras formais, no entanto, não são suficientes para barrar avanços autoritários. Instituiçōes informais também importam. A perspectiva não é nova e remonta aos trabalhos de North (1990) e O’Donnell (1991). É a partir disso que os autores construíram o quinto capítulo, "As grades de proteção da democracia", central no argumento deles. A questão colocada é que as regras formais, que estabelecem o sistema constitucional de freios e contrapesos dos Estados Unidos, não impedem a concentração ou o abuso de poder. Constituiçôes, conforme os autores, são obras incompletas e podem apresentar ambiguidades; por isso, as regras informais têm papel essencial na preservação da democracia. 
Duas normas informais são centrais na democracia: a tolerância mútua e a reserva institucional. A tolerância mútua é a capacidade que os atores políticos têm de aceitar posicionamentos contrários, mesmo que não concordem. Já a reserva institucional é o ato de evitar que açóes sejam usadas até o limite das prerrogativas institucionais, ou seja, mesmo amparadas na lei, podem cercear a ação do oponente a um limite para além do aceitável.

Não somente o Executivo pode abusar de suas açóes (emitindo decretos presidenciais em excesso, por exemplo), mas também o Legislativo, quando propóe ações de obstrução ou mesmo impóe processos de impeachment, em vez de contornar a situação por outros meios. Em alguns casos, como do Presidente Lugo no Paraguai, em 2012, pode ser denominado de um jogo duro constitucional (constitutional hardball), ou seja, as regras foram utilizadas para tomar uma ação extrema, ainda que legal. No limite, diversos processos de impeachment na América Latina, motivados por crises presidenciais, remetem à falta de reserva institucional dos atores políticos. A polarização política extremada é um dos fatores que levam ao "jogo duro", pois os partidos deixam de ter compromisso com a moderação democrática em nome da exclusão do oponente.

O sexto capítulo, "As regras não escritas da política norte-americana”, dá prosseguimento ao anterior, apresentando exemplos dos Estados Unidos em que os atores agiram contra as regras informais da democracia. Um dos casos conhecidos é o do conflito entre Roosevelt e a Suprema Corte, durante a década de 1930, quanto à interpretação da Corte em relação a alguns aspectos do New Deal, bem como as reeleiçóes do referido presidente, que quebraram uma normal informal (mas não constitucional) de que o presidente dos Estados Unidos somente poderia ser reeleito uma única vez. Após os quatro mandatos de Roosevelt, aprovou-se a Emenda Constitucional no 22, a fim de evitar que presidentes infringissem essa regra garantidora da alternância no poder.

Outro aspecto importante, levantado pelos autores, foi a aceitação de democratas e republicanos como rivais legítimos. Apesar de serem oponentes, os partidos aceitavam a regra informal da tolerância mútua, o que, por consequência, influía sobre a capacidade de os atores políticos aceitarem a reserva institucional como um princípio fundamental para o bom andamento das instituiçóes democráticas do país; por isso, processos de impeachment nos Estados Unidos são tão raros.

No sétimo capítulo, "A desintegração", Levitsky e Ziblatt discorrem sobre como as chamadas "grades flexíveis de proteção" (que incluem regras democráticas formais e informais) têm se tornado mais frágeis nas últimas décadas. Trump seria o resultado do próprio processo de desintegração das grades de proteção e das regras informais que protegem a democracia do país. A cooperação partidária vem perdendo espaço para a polarização política descomprometida com a democracia. Nos Estados Unidos, tem preponderado a "política como guerra”, afastando a possibilidade de diálogo em questôes de interesse mútuo entre os partidos.

Os atores políticos têm agido até o limite das normas formais, infringindo as regras informais, para defender seus posicionamentos, colocando em risco a reserva institucional. Uma possível explicação é a ampliação da polarização política, que tem esvaziado as alas mais moderadas dos partidos políticos, principalmente do Partido Republicado, que vem, paulatinamente, se posicionando mais à direita no espectro ideológico. Sobre a ampliação da polarização e, consequentemente, da intolerância partidária, em 2008, com a eleição de Barack Obama à presidência dos Estados Unidos, o então "candidato democrata foi pintado como marxista, antiamericano e secretamente muçulmano”. Ainda hoje existe a crença de que o ex-presidente não é nascido nos Estados Unidos, o que, obviamente, faz parte da intensiva produção de fake news - incômoda realidade nas democracias pelo mundo.

O eleitorado norte-americano se tornou muito mais cindido, assim como os dois partidos. Esse processo vem ocorrendo desde 1960, quando o eleitorado dos dois partidos foi se tornando cada vez mais homogêneo, o que reforçou a polarização política, tornando muitas pautas praticamente inconciliáveis. Atualmente, os republicanos são, puramente, conservadores, e os democratas, eminentemente, liberais. Os democratas se tornaram o partido das minorias étnicas e dos eleitores seculares, enquanto os republicanos representam boa parte dos eleitores de classe média brancos e dos 
cristấos evangélicos. Houve uma cisão em termos de raça e religião, não somente ideológica.

Donald Trump, atual presidente dos Estados Unidos, ganhou um capítulo ("Trump contra as grades de proteção"), o penúltimo do livro, que trata de seu papel nesse processo de corrosão das regras democráticas informais. Trump é considerado, pelos autores, um modelo típico de líder autoritário, por se enquadrar em três características: (1) por demonstrar hostilidade contra os árbitros, ou seja, com quem exerce o controle; (2) por agir contra importantes players do sistema político, como a mídia; e (3) por tentar alterar regras que geram uma situação adversa aos adversários, como a "criação da Comissão Presidencial de Aconselhamento sobre Integridade Eleitoral”, que pode levar à restrição do direito ao voto de minorias, que são a base do eleitorado do Partido Democrata.

O último capítulo, "Salvando a democracia", apresenta possíveis soluçóes para impedir que a democracia americana corra riscos. Para Levitsky e Ziblatt, a Constituição dos Estados Unidos não imuniza o regime contra açóes antidemocráticas. Para isso, seria preciso minar as bases da extrema polarização política que leva adversários a se tornarem inimigos. A ideia seria a construção de "uma ampla coalizão pró-democrática”, aproximando grupos a partir de uma base moral comum pró-democrática.

Para tanto, um problema central nos Estados Unidos, que pode ser mitigado, é a desigualdade social, que atinge tanto minorias raciais quanto a classe média norte-americana, com as "políticas sociais que beneficiem a todos". Políticas com foco universalista poderiam "reduzir a desigualdade econômica que abastece ressentimentos e polarizaçóes, mas também contribuir para a formação de uma coalizão ampla durável”.

Em uma ação nesse sentido, o Partido Democrata teria um trade-off: ao se aproximar mais do eleitorado de classe média e diminuir a ênfase nas questôes das minorias, que inclui a causa migratória, por exemplo, pode perder o apoio de sua base, o que possivelmente levaria à não mobilização nas próximas eleiçóes. Ao mesmo tempo, não é certo que o eleitorado republicano mais moderado apoie uma candidatura presidencial democrata por receio de risco à democracia ou por confiar em uma plataforma mais universalista. Em relação ao Partido Republicano, as mudanças internas que empurraram o partido mais para a direita geram custos altos à reversão dessa trajetória.

É provável que a polarização política exacerbada seja o novo normal. Mas é certo que os insiders partidários têm um papel essencial em criar as condiçôes básicas para a democracia: selecionar líderes que joguem com as regras da democracia. Para além disso, os atores políticos devem compreender que a reserva institucional e a tolerância política são regras que mantêm os partidos como players relevantes e legítimos na condução do jogo democrático.

\section{Notas}

1 Steven Levitsky esteve no Brasil em agosto de 2018 para divulgaçáo do livro. Em palestra ministrada no Instituto FHC, utilizou o modelo de análise criado com Daniel Ziblatt para caracterizar o então candidato, e agora presidente, Jair Bolsonaro, como um líder com características autoritárias, o que poderia impor riscos à democracia brasileira.

\section{BIBLIOGRAFIA}

LINZ, Juan. (1978), The breakdown of democratic regimes: crisis, breakdown, and reequilibration. Baltimore, Johns Hopkins University Press.

NORTH, Douglass. (1990), Institutions, institutional change, and economic performance. Cambridge, Cambridge University Press.

O’DONNELL, Guillermo. (1991), “Democracia delegativa?”. Novos Estudos Cebrap, 31: 25-40.

PRZEWORSKI, Adam; ALVAREZ, Michael; CHEIBUB, José Antonio \& LIMONGI, Fernando. (1997), "O que mantém as democracias?”. Lua Nova - Revista de Cultura e Politica, (40-41): 113-135. Disponível em: <http:// www.scielo.br/pdf/ln/n40-41/a06n4041.pdf>. Acesso em: 15 nov. 2018. 